\title{
For the public good or just good publicity? Celebrity diplomacy and the ethics of representation
}

Lauren Kogen

Department of Media Studies \& Production, Temple University

This is an Accepted Manuscript of an article published by Taylor \& Francis in Mass

Communication and Society, available online here.

To cite: Kogen, Lauren (2015). For the public good or just good publicity? Celebrity diplomacy and the ethics of representation. Mass Communication and Society 18(1), 37-57. 
Abstract: Celebrities in recent years have taken on a more active role in communicating global humanitarian crises to the American public. This role at times shifts between journalist, advocate, philanthropist, and personal publicist. This paper evaluates how three of the most wellknown celebrities in this genre in the United States - Angelina Jolie, George Clooney, and Bono - differ in their method of speaking about these issues, focusing on how their public discourse adds to, or detracts from, citizens' abilities to understand, discuss, and respond to the issues presented in the public sphere. Through critical discourse analysis, similarities and differences are teased out and placed within the context of previous research on celebrity diplomacy and humanitarian crises, in order to evaluate the usefulness of such performances for the U.S. public as democratic citizens, and for the victims of foreign suffering the celebrities purport to represent.

Keywords: Communication, media, discourse analysis, celebrity diplomacy, activism, donations, distant suffering, human rights, ethics, Africa 
On March 28, 2007, Mia Farrow co-authored an op-ed piece in the Wall Street Journal in which she not only accused the Chinese government of funding the conflict in Darfur, but also chastised another celebrity, Steven Spielberg (then artistic adviser for the 2008 Summer Olympics in Beijing) for not doing enough to stop them. Did the director of Schindler's List, Farrow asked, really want to "go down in history as the Leni Riefenstahl of the Beijing Games?" (Farrow \& Farrow, 2007). Spielberg quickly wrote a letter to Chinese president Hu Jintao asking him to change his position on Darfur, and withdrew from his role in the Olympic ceremonies a year later when his demands were not met.

Such events depict a new world of "celebrity diplomacy" (Cooper, 2008) in which celebrities take an active role in advocating for particular actions or policies related to foreign affairs, and present them to the American public. This trend has been celebrated, criticized, and mocked by scholars, the activist community, and the popular press (e.g. Gilmore, 2003). This paper questions some of the implications of this trend. Namely, how might celebrity discourse on the topic of foreign crises shape audiences' understanding of the world of the other in relation to their own, and to their everyday lives? How might it shape the audience's mediated interactions and experiences with these victims? What do these constructions mean for the public sphere discussion of these issues, and potentially for U.S. engagement with foreign crises? I explore these questions through a critical discourse analysis of the television interviews of three of the most well-known celebrities in this genre - Angelina Jolie, George Clooney, and Bono between 2001 and 2009. A detailed explanation of the choice of these three celebrities is included later in the paper.

I ultimately argue that the way these celebrities present information is problematic, and at times both reinforces narratives surrounding the global other and eschews the power dynamics 
that have played a part in the continuing disadvantages of developing nations, therefore perpetuating simplistic assumptions about both the nature of foreign suffering and ways to address it. These narratives thus have the potential to not only shape how audiences understand these issues, but also how they understand their relationship to, and experiences with, the global other more broadly.

\section{Celebrity diplomacy - useful or dangerous?}

Celebrity diplomacy is a widespread and entrenched phenomenon. To dismiss it as a simple exercise in ego or an inflated sense of self-importance ignores not only the historical connection between celebrity and politics, but also the potential usefulness of celebrities in bringing public attention to political issues. The United Nations was perhaps one of the first institutions to recognize the potential of recruiting celebrities to speak about international crises, and started its "Goodwill Ambassadors" program (of which Angelina Jolie is now a member) in 1962, beginning with the comedian Danny Kaye.

According to Street (2004), it is unsurprising that the public is willing to listen to celebrities speak about politics. Celebrities (in many cases) are attractive, speak eloquently, and speak passionately. For better or worse, the public uses these kinds of criteria to evaluate politicians, and evidence of this can be seen in the number of celebrities that have been elected to public office (Turner, 2004).

Marshall (1997) argues that celebrities function as a symbolic agent for the public in the public sphere. The celebrity represents a collective identity of the public, in which an articulation of culture is embodied. Audiences therefore grant the celebrity the status of "proxy," or agent, in the public sphere (p. 243). Turner (2004) similarly argues that such practices allow audiences a 
means of understanding and synthesizing the constantly-changing world around them, and Smith (“Celebrity diplomacy,” 2009) adds that social communities frequently rally around a celebrity they feel represents their interests, creating a powerful linkage between the public, the public sphere, and these figures.

But the merits of celebrity diplomacy continue to be debated, leading to the question, as was posed at a 2009 conference at the University of Southern California, of whether "on balance, [celebrity diplomacy] has been a good thing" (“Celebrity diplomacy," 2009, p. 9). There is certainly evidence for both sides.

On one hand, as described above, both politicians and NGOs have found celebrities useful in helping their causes. Most activists agree that celebrities help get stories covered that would not have otherwise drawn attention from the press. One public affairs officer of the NGO 'Save the Children' stated that "you can talk about it and you can have a community service announcement and you can have a wonderful little ad and the money is going to all these wonderful things, but until you've got a celebrity or a photo-worthy person up there to sell it, it's going to be a steep hill..." (Cottle \& Nolan, 2007, p. 868). Celebrity interviews provide anecdotal evidence for this. After an interview with Angelina Jolie by CNN's Anderson Cooper, for example, donations for UNHCR (the U.N.'s refugee agency) spiked by $\$ 500,000$. Similarly, after George Clooney went on Oprah in 2006, contributions to UNICEF rose 20\% (Boustany, 2007).

Anecdotes aside, it is often easier to critique such celebrities for their self-importance than to celebrate them. When Mia Farrow offered herself up in exchange for the freedom of one of Darfur's rebel group leaders, or when Brad Pitt, Jennifer Aniston, and Danny DeVito traveled together to Israel to help resolve the Israeli-Palestinian conflict, or when Dennis Rodman 
announced that because of Barack Obama's refusal to meet with Kim Jong-un it was "left to [Rodman] to smooth things over" with North Korea (Levenson, 2013), they were derided as naïve by the press. Such stories provide welcome fodder for critics who argue that the voices of knowledgeable politicians “can't compete with an electric guitar" (qtd. in Moyo, 2009, p. 27); that "the idea that these insulated and bubble-headed people should help make policy is ridiculous" (qtd. in Dowd, 1993, p.1); or that "the prospect of DeVito sitting down to talk peace with Hamas militants over a cup of sweet tea... is preposterous" (Gilmore, 2003).

Some evaluations of celebrity activists go further than pinning upon them the sin of hubris. These mainly center on celebrities' tendency to oversimplify issues, and their ability to seize control of policy decisions. West and Orman (2003) argue that celebrities are often instinctually "endowed with expertise" when they are asked their opinions on policy issues, which often leads them to offer citizens "false choices [and] polarized options" (p. 113). Dieter and Kumar (2008) go so far as to say that celebrities make the situation worse for Africans by making "one-dimensional" recommendations which will "paralyze the initiative of individuals rather than [empower] them" and "may even produce a beggar's mentality" (p. 261).

Kellner (2003) worries that celebrity diplomacy has turned toward the spectacle - toward media-friendly appearances that have dubious effects on decision-making. He argues that this trend has been on the rise since the 1960s, and reached its current apex with the 2008 Obama presidential campaign and social media memes like the "Yes, We Can" YouTube video. In a world of diplomacy-as-spectacle, Kellner sees both politicians and celebrity use the media "as an instrument to push through their issues or agendas," and leading us to "substitute spectacle for substance and engage in symbolic politics rather than the hard work of diplomatic policy 
formations and debate, compromise, and the laborious work of implementation" ("Celebrity Diplomacy," 2009, p. 21).

Media discourse on humanitarian crises, both by celebrities and by others, may also have subtler consequences regarding how Americans think about the developing world. The literature suggests two key concerns here: presenting the global sufferer as 'other,' and presenting the United States as 'hero.' These critiques have not typically been tied to celebrity appearances, but rather to development theory more broadly. They are critical to the arguments made in this paper because they provide evidence for long-established stereotypes that indicate things never change - that the roles of the West and the developing world are 'fixed' and cannot be changed through political action.

Presenting the global sufferer as 'other': Theorists like Stuart Hall (1997) and Edward Said (1994) have gone a long way in breaking down the assumptions embedded about self and other in U.S. political discourse since the era of decolonization. Nonetheless, tropes about those in the developing world continue in a modified form, and the media have been accused of presenting developing nations as 'lesser' than the West in several respects. Various empirical studies have shown that there is an emphasis on 'bad news' in developing regions such as Africa (e.g., Chang, Shoemaker \& Brendlinger, 1987), and that the Western media create an impression of Africa as "AIDS-ridden," "weird," and "falling apart" (Fair, 1993, p. 5).

Presenting the U.S. as 'hero': Other critics point out the media's tendency to paint the United States unproblematically as savior and hero. Beginning with Frank (1966) many scholars and economists have argued that international trade policies instituted by the West have had harmful effects on developing economies, and moreover work to maintain and reinforce power relations between the West and the formerly-colonized nations. Edward Said (1993) argues that 
instead of acknowledging this the U.S. media convey a sort of "moralistic triumphalism" which makes "the average American feel that it is up to 'us' to right the wrongs of the world, and the devil with contradictions and inconsistencies" (p. 55). Others have argued that such rhetoric, when it is used by public officials, works at a fundamental level, and lays the psychological groundwork for more palpable acts of imperialism, indicating the United States knows what is

best, or has a global policing role that exempts them from rules of international law applicable to the rest of the world (Chomsky, 2003; Hardt \& Negri, 2000).

\section{Aims of the study}

Given that there are clearly pros and cons to the celebrity diplomacy trend, this paper attempts to address two pieces of the debate. First, the paper asks how celebrities portray the global other, and whether that portrayal is fair, moral, and accurate. In other words, how do celebrities tell audiences to think about the world of the other, and how to understand that world in relation to their own everyday lives?

Second, the paper explores how three celebrities' media performances contribute to the U.S. public sphere with respect to debate and discussion of the issues and of potential policy responses. In other words, the news media are meant, at least in part, to help audiences engage with issues that are foreign to them, to help them discuss the issues and potential efforts to address them. Therefore one question that ought to help determine whether celebrity diplomacy is a "good thing" should be whether celebrities help the media in this effort. Specifically, do these celebrities address their American audiences as democratic citizens capable of understanding the problem and utilizing the information they are given, or are their appearances simply "spectacles," meant to provide moving, horrifying, passionate, or emotional moments for 
the audience (and the celebrity), but which only allow for superficial engagement with the topic? How do these celebrities therefore shape the audience members' own experiences in the public sphere?

The meanings assigned by these celebrities to the everyday social context of the viewers has implications not only for how viewers might engage with the particular topic discussed in the interviews, but also for how viewers construct their understanding of their relationship to, and experiences with, the other more broadly. Kellner (2003) asserts that "the future will depend on... how democracy can be reconstructed and reinvented in the face of the continuing reign of the spectacle" (p. 177). This paper asks what role democracy, and the public sphere, are being given by these celebrities engaging in a spectacle centered on foreign drama.

\section{Methodology}

Frames and patterns embedded in our everyday discourse are, unfortunately, not always easy to see. The American public, including this author, have been so frequently exposed to this kind of discourse that a special effort needs to be made to make the underlying assumptions visible. When one does not know prior to analysis what kinds of discourse to expect or to look for, critical discourse analysis (CDA) allows for identifying patterns as they emerge. CDA assumes that a large part of how we understand the world develops through our exposure to the media, and the imperceptible ways that the media "construct" reality (Kraidy, 2009, p. 346). Deconstructing those meanings reveals the assumptions and prejudices found within discourse, and hopefully allows us to begin to push against them. CDA accomplishes this partly by looking at the way subjects within a text are constructed (Wood \& Kroger, 2000) or by examining issues of social inequality - either how inequalities are presented through text or how they might arise 
from particular uses of text if they become accepted and normalized (Van Dijk, 1993). This includes "political, cultural, class, ethnic, racial and gender inequality" (Van Dijk, 1993, p. 250). Van Dijk describes CDA as focusing on "the role of discourse in the (re)production and challenge of dominance" (p. 249).

In other words, it is tremendously difficult to escape patterns in language that suggest anything other than a mainstream perception of our social world. Likewise, when these patterns become normalized and institutionalized over time, discourse which entrenches them is often hard to perceive. The patterns become "natural" and "acceptable" (Van Dijk, 1993, p. 254). As Berger and Luckmann (1966) write:

With language, and by means of it, various motivational and interpretative schemes are internalized as institutionally defined - wanting to act like a brave little boy, for instance, and assuming little boys to be naturally divided into the brave and the cowardly. (p. 135)

Styles of 'discourse' naturally 'frame' issues in certain ways, and these two terms are related in that naturalized discourse and frames both embed inherent societal assumptions and play off of common understandings (e.g., Howarth, 2000). The question I ask here is whether assumptions about the global other and about the nature of the political relationship between the United States and the developing world are embedded in the discourse of these celebrities when they speak to American audiences. How might the audience's everyday interactions and experiences with these victims, which occur through the media, be shaped by celebrity discourse? For example, how were victims treated in the text, and how might that define the relationship between reader and victim for U.S. audiences? Are the victims treated as empowered political actors that are on the 
path to their own recovery; as helpless and in need of money, food, and clothing from the global community; or something in between?

Comparisons ease the challenge of CDA. Looking at the differences in how particular celebrities talk about these crises makes the peculiarities of each more visible. As Entman (1991) observes, comparing stories that have the potential to be reported on similarly, but are not, helps reveal the "critical textual choices that framed the story but would otherwise remain submerged in an undifferentiated text" (p. 6). By comparing, argues Entman, frames that would have otherwise seemed natural begin to stand out. For example, by comparing the three celebrities it becomes easier to see, as will be shown in the next section, that Angelina Jolie uses children (including her own) to frame our moral obligation to help, but in doing so embeds a particular discourse on the child-like quality of victims generally, feeding into historical discourses on the underdeveloped 'other.'

The analysis was inductive, based on my own systematic and in-depth analysis of the articles, not a multi-coder content analysis. My research questions were sufficiently broad to allow for an emergent analysis in which I could observe patterns and themes without a predefined schema. Without a priori assumptions about the style the discourse would take, I base the patterns elaborated on in the analysis on the overriding form and function of the interviews in terms of how they construct meaning with respect to the relationship between the audience and the global other. While the nature of CDA does not guarantee that others reading the same text would come to the same conclusions, I support my own with illustrative examples from the data.

Three celebrities were chosen for this study. They were chosen, in part, because they all qualify as what Andrew Cooper (2008) has called "celebrity diplomats," meaning they engage with the issue of foreign suffering at a policy level and on a global stage. My aim here is, in part, 
to understand how celebrities communicate foreign suffering as a policy concern, with potential political responses. It therefore makes the most sense to look at celebrities with a policy focus to their work, rather than, say, Leonardo DiCaprio or Sean Penn, who work primarily for charitable organizations (others' or their own).

Jolie and Clooney have both been selected by the United Nations to take on these policy advocacy roles. Jolie is a Special Envoy for the United Nations High Commissioner for Refugees (UNHCR), focusing her work on policy advocacy regarding the plight of child refugees around the world; George Clooney is a United Nations Messenger of Peace, focusing on raising awareness about mass atrocities and U.N. peacekeeping missions around the world, and the ongoing violence in Sudan and South Sudan in particular. Bono, the most involved in foreign policy of the three, has achieved a level of respect in this arena that, for someone coming from the realm of popular culture, is arguably unrivaled, focusing his policy efforts mainly in the areas of debt relief and the HIV / AIDS pandemic, but also addressing a variety of other issues, many of which are featured on his ONE campaign website. Cooper (2008) refers to the "bonoization of diplomacy" as a new model for diplomacy - arguing that Bono is both insider (respected in politics) and outsider (a pop culture symbol), but that this balance is difficult for most celebrities to attain. Bono is unlike others, according to Cooper, in his ability to use his celebrity to gain audiences, but also maneuver in the political realm through one-on-one meetings with high-level politicians and by understanding global politics well enough to be able to play stakeholders off one another (Cooper, 2008, pp.49-51). Though he has his critics (see, for example, Dieter \& Kumar, 2008), he is well respected by many in the humanitarian aid field, has been using his fame to promote his causes of interest for over 20 years (Vallely, 2006), and has been nominated for at least one Nobel Peace Prize (McQuail, 2005). He has also received the bulk of the 
attention in the scholarship on public diplomacy (e.g., Cooper, 2008; Dieter \& Kumar, 2008), and therefore merits attention here.

The second reason these celebrities were chosen is that they are heavily visible in current popular culture (see, for example, Sherwin, 2008; "Star Currency," 2009). The aim of this analysis is to understand how these issues are being portrayed to average American audiences not the political and intellectual elite or those who seek out foreign news. These are the stars that are asked to appear on the Today Show rather than PBS' News Hour, because the Today Show's producers know that they will garner their target audience - mainstream Americans that have time for a brief glimpse of current events and culture as they prepare for their work day (Johnson, 2005).

Only television interviews were analyzed. This is because most Americans (73\%) get their information from the national networks and cable channels (Purcell et al, 2010), and the aim here was to evaluate how celebrities construct meaning for mass, mainstream audiences. Transcripts of interviews with these three celebrities, from January 2001 (the first year that all three were speaking publicly on these issues) to September 2009 (the most recent data available at the time of the analysis), were gathered using a Lexis Nexis search. ${ }^{1} 13$ interviews with Angelina Jolie, 13 interviews with George Clooney, and 18 interviews with Bono were found. All interviews were used in the analysis.

\footnotetext{
${ }^{1}$ A search of network and cable news transcripts was conducted with the following keywords: "interview w/5 (Bono or "Angelina Jolie" or "George Clooney")." Some of the results were not formal interviews - they were either excerpts from other interviews or teasers for shows. Therefore any transcript that was an excerpt or duplicate of another interview, or included less than 60 words from the celebrity, were omitted from analysis.
} 


\section{Findings}

The three celebrities frequently describe these crises to American audiences in terms of their own experiences. However, a close reading of the text made it clear that the celebrities' stories invoke particular meanings pertaining to the relationship between the West (usually the United States) and the other. Two recurring patterns were particularly salient - one pertaining to how the celebrities define the power relationship between Westerners and victims and one pertaining to how the celebrities define the viewers' potential political engagement with the other:

1) Discourse of Condescension: Discourse which entrenches historical narratives regarding the global other, including presenting the global other as child, as eternal victim, as intellectually and politically undeveloped, or as too bizarre to comprehend, or narratives regarding the United States or the West as parent, eternal hero, or savior;

2) Discourse of Inefficacy: Discourse which promotes hopelessness and unhelpful pity by excluding practical solutions or ways to change the dynamics that are at the core of many of these crises.

The first of these frames corresponds to an old and ongoing global discourse which frames Africa as 'other,' as described in the previous sections, but which has not been applied to discourses surrounding celebrity diplomacy. The second, emerging from a close reading of the text and attention paid to how the information presented might contribute (or not) to the public sphere, provides a new perspective on a potential harm celebrities may be unintentionally inflicting both on audiences and victims. Celebrity presentations that deny the audience the information necessary to properly discuss the problem, that in fact portray the problem as not having potential political responses, do a disservice to U.S. audiences by removing the topic 
from the public sphere, thereby limiting audience engagement to pity or charitable donations, and defining the viewer as unable to engage with the global other in any other way. The excerpts in the following sections represent typical responses of the celebrities. When appropriate I include information about the total number of interviews that follow each pattern.

\section{Discourse of Condescension: Heroes and helpless victims}

Repeatedly in these interviews, the celebrities portrayed the relationship between the United States and the rest of the world as one of helper and helpless. The United States was frequently presented unproblematically as 1) having no role in the crisis or leading up to it, and 2) as beneficent, powerful, and able to "fix" everything through diplomacy. For example, in a 2008 interview on Late Edition with Wolf Blitzer, Clooney observed that:

It's interesting how quickly things aren't hopeless when people, a group of people, American citizens, European citizens, suddenly stand up and say, wait a minute, let's take a look at this. (Feist, 2008)

This is one example of many found in which the celebrities frame the United States or Europe as best placed to help, and as having a reputation for helping. The role of the United States in the conditions leading up to suffering, or the policies that exacerbate it, is therefore obscured. Clooney made a similar comment in an interview with Larry King, noting that, rather than donating monetary aid, "It's about needing what we do best, what we have done best since the start of this country, which is good, robust diplomacy all across the world" (Douthit, 2009). 
Jolie has similarly argued that "we are missing a lot of opportunities to do a lot of the good that America is used to doing, has a history of doing" (Pearsall, 2006), and Bono that he wants to remind audiences "why the [United States] is great" (Tabacoff, 2004).

The goal of all three celebrities seems to be to make audiences proud of their country, to inspire them to act, but this construction implies that the United States has (almost) always supported the global poor. Bono's contention that "the United States that I love is like the Statue of Liberty with its arms open, give me your tired, your poor and huddled masses," belies the fact that the United States frequently acts in its own interests at the expense of the global other, often exacerbating the very issues these celebrities are calling on us to address (Tabacoff, 2004).

Furthermore, these descriptions of United States as eternal savior often overlap with, or are paired with, a description of the United States as parent and guardian, or the victims of these crises as helpless, less knowledgeable, and more child-like. In many cases it is not so much what the celebrities say about these victims, but what they do not say. In presenting the innocence of the victims, there is a tendency to speak about the global other that is reminiscent of the early development paradigm. The adjectives that are used to describe them are almost always associated with basic, primal, instincts and emotions: despair, hope, bravery, vibrancy, beauty. There is little to no acknowledgement of intellectual or political capability, or efforts toward protection or peace that are being made by the societies in conflict themselves.

For example, when Jolie states that the United States needs to "be there to really support them at that time, to help them to understand how better to govern" (Pearsall, 2006), or to "teach them about law; teach them about having their own health care; teach them about ourselves; teach them about the world" (Pearsall, 2009), she is also teaching her audience how to think about these victims. The implication is that these victims need to be 'taught' by the United States 
because what they are lacking is knowledge. If only they knew about the kinds of systems the United States and the West had in place, they would surely recognize them as superior and adopt them posthaste, and their problems would begin to dissipate. This frame suggests that the relationship is one similar to that between parent and child, not one influenced by things like international trade policies, debt obligations, and the motivations of outside players. Only two of the celebrities (Jolie and Bono) mentioned victims as having any political agency at all, and did so a total of three times in the set of interviews: Jolie told the story of a man in Myanmar teaching others how to farm (Pearsall, 2007) and Bono on two occasions describes Africans as "entrepreneurial" (Douthit, 2006; Goldston, 2007). These were however, fleeting references. The overriding trend was to describe victims as innocent and in need of guidance. In one interview with Bono on The O'Reilly Factor, Bill O'Reilly (embodying the attitude of the African as in need of guidance) asks Bono why we should spend tax dollars on AIDS in a "civilization or a society that no matter what you tell them, they're going to continue to do disruptive practices" (Pepper, 2006). Bono attempts to address O'Reilly's concerns:

Look, if you see a car crash, somebody's lying there in the middle of the road bleeding and it turns out they're a drunk driver, you're still going to call an ambulance. We can't make these judgments about entire civilizations. We try to re-educate people, we try to deal with the problem. (Tabacoff, 2004)

While Bono is indeed trying to indicate that O'Reilly and others cannot make generalizations about entire regions, neither Bono nor the other two celebrities analyzed here make significant attempts to provide counter examples to this kind of portrait, nor do they provide descriptions of Africans as aware of and engaged with their own political future. 
This is not to say that most descriptions of victims were not complimentary. In fact, the celebrities seem to go out of their way to emphasize the positive characteristics of victims. Jolie and Clooney frequently describe victims as 'just like us,' as people just trying to survive, and to protect their children. During an interview on Dateline in 2006 Jolie stated that:

People often look at people like this in these situations and they think that they're not exactly like us, you know?... They're very smart. They're very - they take care of their families... They love their children... and they want them to go to school. (Pepper, 2006)

Similarly, in an interview with Anderson Cooper, she noted that the victims she works with are "passionate," "tough," and "vibrant" (Pearsall, 2006). The emphasis on the internal character of these victims, while complimentary, suggests that their engagement with the problem is limited to their strong resolve and commitment to muscle through the tough times. Likewise, Clooney, describing rape victims in Darfur, told Today Show viewers that "the courage that this little corner of a [hospital] room has will not be lost on the rest of the world (Michaels, 2008).

These celebrities would no doubt argue that their intention is to make American citizens realize that human beings are all the same, that the relationship between the West and the rest is one of equals, and therefore that distant sufferers are worthy of compassion. However, the comparison is only between human beings at their most basic level; victims are portrayed as 'like everyone else' but without the ability to properly understand the context of their condition, or any possible political solutions for it.

For Jolie, gender plays a large part in this kind of discourse surrounding compassionworthy victims, and maternal references pervade her speech. Part of this no doubt lies in Hollywood's obsession with Jolie's children, but she has created a persona for herself both in 
Hollywood and in her humanitarian work as nurturer, protector, and mother. There is an established body of literature on the ways the female and the female body are used to create an idea of nationhood (e.g., Anderson, 1983), and in these interviews notions of Jolie as mother of her own children, Jolie as mother to her victims, and United States as parental guardian to the world fluidly overlap. When she tells audiences that her daughter, Zahara, is "from a country where six million kids don't go to school every year just in her country alone" (Pepper, 2006) she makes it quite clear that her own efforts to protect her daughter parallel her diplomatic efforts to protect millions more like her. In the same vein, she indicates that U.S. efforts to protect the vulnerable at home need to extend to the rest of the world. In a 2006 interview with Anderson Cooper, she states that, unlike American citizens, the victims she works with:

...don't have the protection of their own country. They're somewhere uprooted, without any protection, with their families, relying on somebody to open their doors for someplace for them to lay their head down or get some food or something. (Pearsall, 2006)

She additionally argues that these victims need "healthcare," "protection," and that "they need to be safe" (Pearsall, 2006). While a case could be made that these descriptions certainly apply under some circumstances, hearing these same narratives, repeatedly, defines for the viewer a particular relationship between the United States and these victims. It suggests that we are stuck in a cycle that requires the United States to swoop in and save the developing world from crisis after crisis because these characteristics regarding the West and the rest - the strong protector and the weak in need of protection - are ahistorical and inherent traits of these two worlds, unbound by circumstance. 
Of Jolie's 13 interviews, six include either descriptions of victims using adjectives associated with innocent children or descriptions of the United States as the hero to the rest of the world, while virtually all included a discussion of her own children. Clooney emphasized the other's innocence or U.S. heroism in three of 13 interviews, and Bono in six of 18. Clooney and Jolie never put the United States' 'heroic' role in context, though Bono does several times (which will be discussed further on).

Thus rhetoric which focuses on U.S. diplomatic efforts as the only solution potentially exacerbates historically entrenched attitudes and understandings about 'the West and the rest' at the expense of empowering and acknowledging the ability of those in developing societies to take a proactive role in improving their lot. While civil society in Africa is admittedly weaker than in many parts of the world, there are many local civil society and human rights organizations working to effect change in all areas of political life. In many conflict situations civil society groups are directly involved in peace negotiations. Much work on transnational civil society focuses precisely on how effective these local actors can be (e.g., Khagram, 2000). The discourse of Jolie, Clooney, and Bono presupposes that any local political solutions are secondary to those emanating from the West. It might be argued that if the victims of these crises are not portrayed as completely helpless that Americans will be less willing to support aid, but there is no a priori reason to believe that this is true, or that Americans would be any less sympathetic to the cause if these roles were acknowledged. It is perhaps equally likely that Americans would be less likely to help if they think aid to victims who are unable to change or improve their own status is a waste, such as was suggested by O'Reilly in his interview with Bono, referenced above. 


\section{Discourse of inefficacy}

Perhaps one of the most obvious reasons celebrity spokespersons are used by humanitarian aid groups is the hope that they will be able to convince ordinary citizens to get involved. If, as some scholars argue (e.g., Hoijer, 2004; Kogen, 2009), part of the reason ordinary citizens do not act is because they feel powerless to do anything, these celebrities have the opportunity to demonstrate to their audiences that certain policies, or even individual efforts, can make a difference. Thus, one aim of the analysis is to evaluate whether these "celebrity diplomats" make it clear what U.S. policies, or individual actions, might help.

Previous research has shown that Western publics often appear 'indifferent' to global cases of human suffering. This trend has been blamed on desensitization (Sontag, 1977), psychic numbing (Slovic, 2007), and rational choice theory (Becker, 1996; Kogen, 2009). In their discussions of foreign crises on television or in the press, celebrities often seem to be sending a message that "something needs to be done." However, narratives of inevitability, which frame suffering as permanent and ahistorical, deny the audience members' ability to actively take part in effecting change. While all three celebrities often espoused policy recommendations (in approximately half of all interviews), they were usually broad-sweeping recommendations usually simply that the government should spend more money on aid. Additionally, they rarely mentioned what individual audience members could do, even when asked directly by their interviewers. There were exactly three instances found in the analysis in which the interviewer directly asks what audience members can do, and in no case did the celebrity provide a straightforward answer, or even name a specific U.S. policy audiences could support or oppose.

In one instance Anderson Cooper, echoing the concerns outlined in this paper, asked Jolie what audiences can do when "it becomes this blur of sort of endless suffering in Africa... and... 
people sort of throw up their hands" (Pearsall, 2006). Jolie's response was telling: "Well, I think to acknowledge that and say, yes, it is another -- we understand that"' (Pearsall, 2006).

When Clooney was asked what audiences could do in his Good Morning America interview, his response was equally opaque:

Mm-hmm. Through church groups and organizations, you can pick up the phone or e-mail or you can, you know, write a letter directly to your senator, and you can really make a difference because that does actually matter to the people... It empowers them. (Funk \& McKinnon, 2008)

Not only is it unclear whether Clooney refers to Americans or Darfuris who are "empowered" when someone writes a letter to a Senator, but how could the American citizen feel empowered when Clooney has not told them which legislation they should be supporting?

Bono's strategy is to keep the finger pointed at the U.S. government, rather than individuals. When Bill O’Reilly asked what Bono wanted Americans to do about AIDS and HIV, Bono replied, "I'm not asking drug companies to behave like philanthropists. I'm saying we, our governments, United States and Europe, have to deal with this problem" (Tabacoff, 2004).

While both Clooney and Bono reference the need for government action, none provide a clear message to their audience, despite their supposed position as policy advocates. When interviewers ask such questions, it would imply that they believe their audience wants to help, and desires to know what they, as individuals, perhaps as voting citizens, can do. It is, in fact, a natural response. There is a moral angst brought about when audiences hear such stories, and it is that compassion that these celebrities seem to be intentionally eliciting in their speech. For these celebrities to offer an image of atrocities, to speak as experts, and then hesitate when asked what 
help their audience members can provide, borders on irresponsible. How can the audience member not then come to the conclusion that there is little to be done by individuals?

\section{Working toward a more ethical framework}

Given their power to attract and hold the attention of audiences, celebrities ought to facilitate, rather than obscure, Americans' understanding of foreign crises. While it is not the responsibility of celebrities to provide history lessons on international trade regulations, they should, at the very least, refrain from presenting the distant sufferer as helpless, U.S. public engagement as irrelevant, or the United States as infallible. Three overarching recommendations summarize the ways in which these celebrities can and should modify their discourse:

Emphasize context over helplessness. Evoking sympathy and compassion for sufferers is not problematic in itself. It becomes problematic, however, when this is done by evoking helplessness and desperation, or by emphasizing the sufferer as feeble, childlike, or underdeveloped. This can easily be remedied by discussing the unfortunate context of the situation without associating that emotion with a judgment of the victim's character.

While all three celebrities analyzed are guilty at some level of portraying victims as helpless, Bono's more recent discourse is much more likely than either Jolie's or Clooney's to discuss context. Bono's comments such as his analogy between Africans and drunk drivers have virtually disappeared from his interviews in recent years, and he rarely speaks of sufferers with Jolie's adjectives of innocence. When he speaks about AIDS, one of the causes in Africa he discusses most frequently, he almost exclusively focuses on the practical aspects of the situation at hand. In the interviews analyzed here, Bono frequently does this by emphasizing the ease with which the situation could be addressed. In one interview he told Larry King that "two-and-a-half 
million Africans are going to die next year for the stupidest of reasons, because it's difficult to get the AIDS drugs to them" (Douthit, 2006), and in an interview on Nightline he refers to a "stupid poverty" that "has a family lose their life because of a 20 cent immunization" (Goldston, 2007).

In contrast, Clooney and Jolie virtually never mention the on-the-ground context of the crisis. Clooney makes certain references to indicate that fighting is occurring, and Jolie in one case discusses a hospital she visited that needed basic equipment (Pearsall, 2006), but for the most part Clooney and Jolie speak almost exclusively about the victims' hope, fear, suffering, and strength, and that the West should (somehow) help. ${ }^{2}$

Emphasize the power of individuals over the power of the West. Audiences can engage with these issues directly, a fact too frequently elided by these celebrities. Bono far more frequently than the other two discusses political action. Aside from a 2002 interview with Oprah (Hudson, 2002) in which he told audiences to support then-Secretary of the Treasury, Paul O’Neill, in providing more foreign aid, his early interviews generally made no mention of what ordinary Americans might do. Recently, his calls for personal action have become more frequent. However, they remain indirect. He generally solicits action only by pointing audiences to his website or by promoting products from his RED ${ }^{\circledR}$ campaign (which donates a portion of its proceeds to AIDS work in Africa), which has brought him some heavy criticism (e.g., Yrjölä, 2009). Promoting consumerism may not be the best way to even out global inequalities at least in part brought on by a capitalist system; nonetheless, this effort to connect the potential alleviation of global suffering to the actions of individuals stands in stark contrast to the discourse of the

\footnotetext{
${ }^{2}$ Jolie's approach is different in her written pieces for the elite press, which are not discussed here. However, it is the underlying assumption of this paper that these celebrities can do much to effect change in the general population, through the popular, mainstream media. The discourse of all three, but Clooney and Jolie in particular, continues to fall short in this regard.
} 
other two celebrities. Bono's website, for example, tells viewers how to effectively write letters to their congressmen on particular topics, or to their local newspapers.

Acknowledge the historical role of the West. It is also possible to acknowledge the role of the West in the modern global economic landscape. While celebrities cannot be expected to give a lesson on colonialism during their interviews, it is possible to introduce history or current economic incentives in ways that are palatable to audiences. Clooney and Jolie have each made fleeting references to history. Bono's primary way of doing this is to talk about debt relief. $\mathrm{He}$ believes that trade inequalities and the debt owed to the West by African nations present fundamental hurdles in the restructuring of postcolonial relations. In an interview with Larry King Bono explained that "Africa was paying much more back to the Western world servicing old debts than it was ever... receiving in aid monies" (Douthit, 2006), and on CNN's American Morning he informed audiences that "we in the West propped up some very dangerous dictators by giving them loans and throwing aid at them" and that we therefore "can't then point to the waste of those resources as just their fault" (Kraft, 2006).

While these descriptions are brief, they at least hint at the idea that U.S. foreign aid can, at times, be more about strategic interests than philanthropy. Communicating that fact to audiences could help them think and discuss both past and potential foreign policy more effectively.

The above analysis suggests that Bono may do a better job than Jolie or Clooney of ethically discussing the global sufferer. Cooper (2008) devotes an entire section of his book on celebrity politics to why Bono is "the talisman of celebrity diplomacy" (p. 36). However, his appraisal of Bono's worth emphasizes his skills as a negotiator, his persistence, and his faithbased appeals, in his work with politicians outside of the public eye. When it comes to public 
discourse, Bono, Clooney and Jolie all offer examples of ways in which celebrity discourse may unintentionally harm efforts at aiding the global other.

\section{Conclusion}

This analysis shows that the rhetoric of these "celebrity diplomats" does a disservice to the victims on whose behalves they speak by 1) entrenching historical narratives of the other as a child, a victim, and politically underdeveloped, and the United States as savior and hero; and 2) narrowly defining for viewers how they can engage politically with the global other.

I do not claim that the ills produced by speaking without the above suggested framework in mind outweigh those posed by not speaking at all. Pros and cons tallied, it is difficult to challenge the claim that simply shedding light on a topic that is receiving insufficient attention is the most useful thing a celebrity speaking about global humanitarian crises can do. Rather, I suggest that the way celebrities speak about these issues could be improved.

The idea of "media imperialism" - that the exportation of media content from more to less industrialized countries reinforces domination and dependence - has been heavily critiqued in the field of communications in the past two decades (e.g., Sreberny-Mohammadi, 1997). However, insufficient attention has been paid to the consumption of Western news media by Western audiences and its effect on narratives of domination and dependence. The purpose of this paper has been to argue that the way celebrities speak about foreign crises entrenches ideas about how different parts of the world should interact with each other.

Celebrities are good at presenting uncomplicated narratives. That is part of their onscreen job description, and that is, at least in part, why they are good at communicating with the public. But often these narratives reinforce mythic dichotomies such as good and evil, or strong 
and weak, without acknowledging that these roles are far more complex and often overlap (see, for example Fiske, 1989, chapter 8).

If it is true that the media today define our moral space, and our moral order, and more so when we discuss global humanitarian crises, we can begin to ask questions about how the media and media audiences ought to act in a globalized world, toward the global 'others' which the media represent and reproduce. Through the analysis presented here, a way to do this begins to reveal itself. This paper has argued that moral action by political speakers includes not only fairly representing the disadvantaged, but also acknowledging the moral principles which many global citizens use to guide their actions (even if these actions only infrequently lead to assisting the distant sufferer). By emphasizing the context of the situation rather than the powerlessness of the victims, emphasizing the power of individuals, and privileging justice over charity by acknowledging the historical role of the West and the current economic incentives that exacerbate suffering, communicators may bring about change through political action, and indirectly through changed perceptions and attitudes. Bono, Jolie, Clooney, and other celebrities who wish to work on international humanitarian issues must do more to avoid entrenching the global power narratives that already exist, and to promote situating the distant sufferer and the American as active agents of change. 


\section{References}

Anderson, B. (1983). Imagined communities: Reflections on the origin and spread of nationalism. London: Verso.

Becker, G.S. (1996). Accounting for tastes. Cambridge, MA: Harvard University Press.

Berger, P. L., \& Luckmann, T. (1966). The social construction of reality: A treatise in the sociology of knowledge. New York: Doubleday.

Boustany, N. (2007, June 10). Hollywood stars find an audience for social causes. The Washington Post, p. 1.

Celebrity Diplomacy: The effectiveness and value of celebrity diplomacy (2009). Panel discussion at the USC Annenberg School for Communication and Journalism. Retrieved from http://www.learcenter.org/pdf/celebritydiplomacy.pdf. http://www.learcenter.org/pdf/celebritydiplomacy.pdf.

Chang, T., Shoemaker, P.J., and Brendlinger, N. (1987). Determinants of international news coverage in the U.S. media. Communication Research 14(4), 396-414. doi: $10.1177 / 009365087014004002$.

Chomsky, N. (2003). Hegemony or survival: America's quest for global dominance. New York: Holt.

Cooper, A. F. (2008). Celebrity diplomacy. Boulder, CO: Paradigm.

Cottle, S., \& Nolan, D. (2007). Global humanitarianism and the changing aid-media field: "Everyone was dying for footage". Journalism Studies, 8(6), 862-878. http://dx.doi.org/10.1080/14616700701556104. 
Dieter, H., \& Kumar, R. (2008). The downside of celebrity diplomacy: The neglected complexity of development. Global Governance, 14(3), 259-264. Retrieved from http://acuns.org/global-governance-journal/.

Douthit, R. (Director). (2006, Oct 13). Larry King Live [Television broadcast]. Atlanta, GA: Cable News Network.

--- (2009, Feb 23). Larry King Live [Television broadcast]. Atlanta, GA: Cable News Network. Dowd, M. (1993, May 9). Washington is star-struck as Hollywood gets serious. The New York Times, pp. A1, A22.

Entman, R. M. (1991). Framing U.S. coverage of international news: Contrasts in narratives of the KAL and Iran Air incidents. Journal of Communication, 41(4), 6-27.

Fair, J. E. (1993). War, famine and poverty: Race in the construction of Africa's media image. Journal of Communication Inquiry, 17(2), 5-22. doi: 10.1177/019685999301700202.

Farrow, M., \& Farrow, R. (2007, March 28). The 'genocide Olympics'. Wall Street Journal, p. A17.

Feist, S. (Executive Producer). (2008, July 6). Late edition with Wolf Blitzer [Television broadcast]. Atlanta, GA: Cable News Network.

Fiske, J. (1989). Television culture. London and New York: Routledge.

Frank, A.G. (1966). The development of underdevelopment, Monthly Review, 17(September), $17-30$.

Funk, D., \& McKinnon, B. (Directors). (2008, Feb 1). Good morning America [Television broadcast]. Burbank, CA: American Broadcasting Company.

Gilmore, I. (2003, Oct 26). After Tony and Kofi fail, Brad and Jennifer try mid-east diplomacy. The Telegraph. Retrieved from: 
http://www.telegraph.co.uk/news/worldnews/middleeast/israel/1445155/ After-Tony-andKofi-fail-Brad-and-Jennifer-try-Mid-East-diplomacy.html

Goldston, J. (Producer). (2007, June 6). Nightline [Television broadcast]. Burbank, CA: American Broadcasting Co.

Hall, S. (1997). The spectacle of the "other.” In S. Hall (Ed.), Representation: Cultural representations and signifying practices (pp. 223-279). London: Sage.

Hardt, M., \& Negri, A. (2000). Empire. Cambridge, MA: Harvard University Press.

Hoijer, B. (2004). The discourse of global compassion: The audience and media reporting of human suffering. Media, Culture \& Society, 26(4), 513-531.

Hudson, D.A. (Executive Producer). (2002, September 20). The Oprah Winfrey show [Television broadcast]. Chicago: Harpo productions.

Howarth, D. (2000). Discourse. Buckingham: Open University Press.

Johnson, S. A. (2005). The art of the author interview and interviewing creative people. Lebanon, NH: University Press of New England.

Kellner, D. (2003). Media spectacle. Routledge, London.

--- (2009). Barack Obama and celebrity spectacle. International Journal of Communication, 3, 715-741. Retrieved from http://ijoc.org/index.php/ijoc.

Khagram, S. (2000). Toward democratic governance for sustainable development: Transnational civil society. In A. M. Florini (Ed.), The third force: The rise of transnational civil society (pp. 83-114). Washington D.C.: Carnegie Endowment of International Peace.

Kogen, L. (2009). Why the message should matter: Genocide and the ethics of global journalism in the mediapolis. Journal of International Communication, 15(2), 62-78. doi: 10.1080/13216597.2009.9674751. 
Kraft, J. (Producer). (2006, June 29). American Morning. Atlanta, GA: Cable News Network.

Kraidy, M. (2009). Reality television, gender, and authenticity in Saudi Arabia. Journal of Communication, 59(2), 345-366. doi: 10.1111/j.1460-2466.2009.01419.x

Levenson, E. (2013, July 2). Dennis Rodman doesn't get why North Korea's his job and not 'the black guy's'. The Atlantic Wire. Retrieved from http://www.theatlanticwire.com/national/2013/07/dennis-rodman-nobel-peaceprize/66794/.

Littler, J. (2008). "I feel your pain": Cosmopolitan charity and the public fashioning of the celebrity soul. Social Semiotics, 18(2), 237-251. doi: 10.1080/10350330802002416.

Marshall, D. (1997). Celebrity and power: Fame in contemporary culture. Minneapolis: University of Minnesota Press.

McQuail, J. (2005, Feb. 18). Bono on list for Nobel Peace Prize. The Mirror (London). p. 19.

Michaels, J. (Director). (2008, February 1). Today [Television broadcast]. Universal City, CA: $\mathrm{NBC} /$ Universal.

Moyo, D. (2009). Dead aid. New York: Farrar, Straus \& Giroux.

Pearsall, K. (Director). (2006, June 20). Anderson Cooper: 360 [Television broadcast]. Atlanta, Georgia: Cable News Network.

--- (2007, June 20). Anderson Cooper: 360 [Television broadcast]. Atlanta, Georgia: Cable News Network.

--- (2009, June 19). Anderson Cooper: 360 [Television broadcast]. Atlanta, Georgia: Cable News Network.

Pepper, G. (Director). (2006, Apr 30). Dateline NBC [Television broadcast]. Universal City, CA: $\mathrm{NBC} /$ Universal. 
Purcell, K., Rainie, L., Mitchell, A., Rosenstiel, T., \& Olmstead, K. (2010). Understanding the participatory news consumer: How internet and cell phone users have turned news into a social experience. Pew Project for Excellence in Journalism.

Said, E. (1993). Culture and imperialism. New York: Knopf.

Sherwin, A. (2008, January 29). U2 manager: Cut off illegal downloaders from internet. Retrieved from FoxNews.com. http://www.foxnews.com/story/0,2933,326251,00.html.

Slovic, P. (2007). "If I look at the mass I will never act": Psychic numbing and genocide. Judgment and Decision Making, 2, 79-95.

Sontag, S. (1977). On photography. New York: Farrar, Straus and Giroux.

Sreberny-Mohammadi, A. (1997). The many cultural faces of imperialism. In P. Golding \& P. Harris (Eds.), Beyond cultural imperialism: Globalization, communication \& the new international order, (pp. 49-68). London: Sage.

"Star Currency". (2009). Forbes Magazine. Retrieved from http://starcurrency.forbes.com/celebrity-list/celebrity-search/?name=\&gender=all\&geography= World+Wide\&rankprof=all\&otherprofs $=$ all\&scoreRangeType=all\&rangel $=\&$ rangeu $=$.

Street, J. (2004). Celebrity politicians: Popular culture and political representation. British Journal of Politics \& International Relations, 6(4), 435-452. doi: 10.1111/j.1467856X.2004.00149.x.

Tabacoff, D. (Executive Producer). (2004, Sept 2). The O'Reilly factor [Television broadcast]. New York: Fox News Network.

Turner, G. (2004). Understanding celebrity. London: Thousand Oaks.

Vallely, P. (2006, May 13). Bono: The missionary. The Independent (London). p. 41. 
Van Dijk, T. A. (1993). Principles of critical discourse analysis. Discourse \& Society, 4(2), 249283. Retrieved from http://das.sagepub.com/.

West, D. M., \& Orman, J. (2003). Celebrity politics. Saddle River, NJ: Pearson Education.

Wood, L. A., \& Kroger, R. O. (2000). Doing discourse analysis: Methods for studying action in talk and text. Thousand Oaks, CA: Sage.

Yrjölä, R. (2009). The invisible violence of celebrity humanitarianism: Soft images and hard words in the making and unmaking of Africa. World Political Science Review, 5(1), Article 14. 